This item was submitted to Loughborough's Research Repository by the author.

Items in Figshare are protected by copyright, with all rights reserved, unless otherwise indicated.

\title{
Microstructural analysis of IN617 and IN625 oxidised in the presence of steam for use in ultra-supercritical power plant
}

PLEASE CITE THE PUBLISHED VERSION

http://dx.doi.org/10.1007/s11085-012-9342-2

\section{PUBLISHER}

(C) Springer Science+Business Media

\section{VERSION}

AM (Accepted Manuscript)

\section{LICENCE}

CC BY-NC-ND 4.0

\section{REPOSITORY RECORD}

Gorman, David M., Rebecca L. Higginson, H. Du, G. McColvin, A.T. Fry, and Rachel C. Thomson. 2014. "Microstructural Analysis of IN617 and IN625 Oxidised in the Presence of Steam for Use in Ultra-supercritical Power Plant". figshare. https://hdl.handle.net/2134/15323. 
This item was submitted to Loughborough's Institutional Repository (https://dspace.lboro.ac.uk/) by the author and is made available under the following Creative Commons Licence conditions.

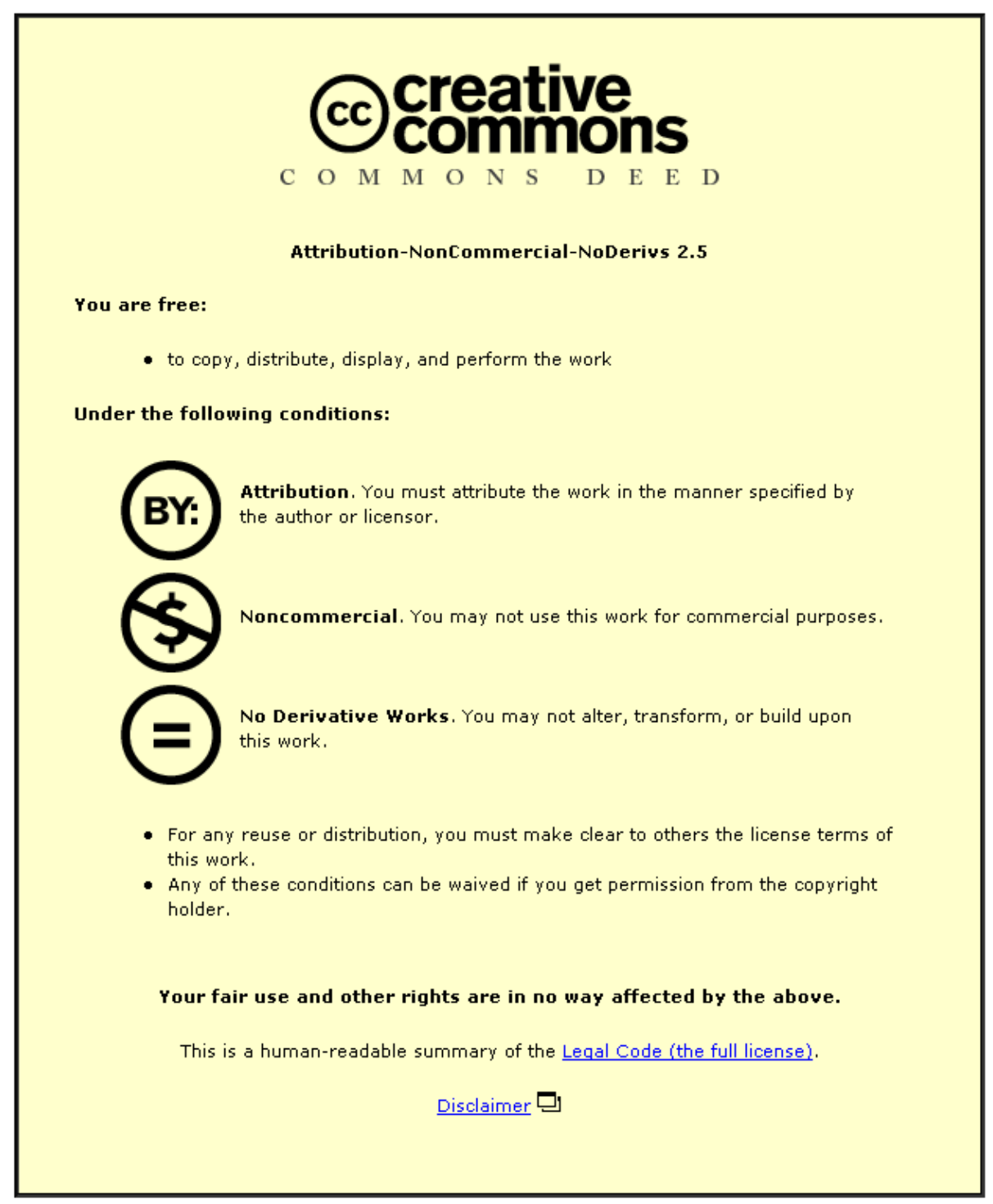

For the full text of this licence, please go to: http://creativecommons.org/licenses/by-nc-nd/2.5/ 


\title{
Microstructural Analysis of IN617 and IN625 Oxidised in the Presence of Steam for use in Ultra-Supercritical Power Plant
}

\author{
D. M. Gorman ${ }^{1}$, R. L. Higginson ${ }^{1}$, Hailiang $\mathrm{Du}^{2}$, Gordon McColvin ${ }^{2}$ \\ A. T. Fry ${ }^{3}$ and R. C. Thomson ${ }^{1}$ \\ ${ }^{1}$ Department of Materials, Loughborough University, Loughborough, Leicestershire, LE11 3TU, UK \\ ${ }^{2}$ Alstom Power, Newbold Road, Rugby, Warwickshire, CV21 2NH \\ ${ }^{3}$ National Physical Laboratory, Hampton Road, Teddington, Middlesex, TW11 OLW \\ d.m.gorman@lboro.ac.uk; r.l.higginson@lboro.ac.uk; hailiang.du@power.alstom.com; \\ gordon.mccolvin@power.alstom.com; tony.fry@npl.co.uk; r.c.thomson@lboro.ac.uk;
}

\begin{abstract}
The nickel based alloys IN617 and IN625 that have been selected for their candidacy in the construction of the hottest regions of the supercritical steam cycle have been oxidised under isothermal conditions at $750^{\circ} \mathrm{C}$ and atmospheric pressure in atmospheres of $100 \%$ steam, 50/50\% steam/argon and air for up to 4200 hours. Both alloys developed a thin protective oxide under each condition. Scale thickness measurements using SEM micrographs were performed and showed that exposures in steam exhibited a higher rate of scale formation than exposures in air in both alloys. IN617 developed an extensive internal network of alumina which resulted in the formation of alloy protrusions into the scale altering scale growth kinetics, IN625 also formed alumina to a lesser extent. Voids formed in the matrix below the scale in both alloys in each environment. The extent of alumina formation alters the void morphology which eventually impacts the scale growth rate as inward scale growth occurred into the voids in IN625 but not in IN617.
\end{abstract}

Keywords: IN617, IN625, Steam Oxidation, Voids, Internal Oxidation

\section{INTRODUCTION}

The effects of steam on high temperature oxidation processes is of technological importance for the construction of next generation high efficiency super and ultra-supercritical steam driven power plants. The typical operating conditions in current coal fired power plants in the hottest regions of a subcritical steam cycle are $\sim 540^{\circ} \mathrm{C} / \sim 175$ bar. State-of-the-art ultra-supercritical $\left(275 \mathrm{bar} / 600^{\circ} \mathrm{C} / 620^{\circ} \mathrm{C}\right)$ plants are offered today where the required material properties are already well established. Further efficiency increases of 8-10 percentage points may be possible with the adoption of cost effective materials available for long term use capable of withstanding temperatures and pressures in excess of $700^{\circ} \mathrm{C}$ and 300 bar. The potential benefits from the construction of such generating facilities are twofold; efficiency improvements will reduce the overall carbon emissions per $\mathrm{kWh}$ and increase the yield from combusted fuels. IN617 and IN625 are two candidate alloys for the construction of key components of the steam cycle, namely, areas which are subjected to the highest temperatures such as the headers and adjoining pipe work.

It is generally understood that the presence of steam impacts on the oxidation processes of a number of metals and alloys, however, there has been little work on the effects of steam on the oxidation of nickel alloys [1,2,3,4]. Saunders et al. concluded that the steam affects multiple aspects of oxide growth including adsorption, dissociation, oxide volatilisation and diffusion of reactants when compared to similar processes in dry conditions and it is these processes that determine the rate of formation, morphology and ultimately the properties of the resulting scale [5].

Microstructural analysis has been carried out to compare and contrast the oxidation features which develop in each alloy under the different conditions to further understand the impact of steam on oxidation processes. 


\section{EXPERIMENTAL PROCEDURES}

The nominal compositions of the nickel based superalloys IN617 and IN625 are given in Table 1. For all exposures, except IN625 in air, the samples were originally cut from rods into coupons approximately $2 \mathrm{~mm}$ thick and $20 \mathrm{~mm}$ in diameter. The IN625 air exposed samples were cut from bar into coupons approximately 10 by 10 by $3 \mathrm{~mm}$ thick. Both alloys exhibited equiaxed grains. The average bulk alloy grain diameter was $50-100 \mu \mathrm{m}$ for IN617 - air and steam exposed samples, and IN625 - air exposed samples. IN625 samples oxidised in steam had a smaller bulk alloy grain diameter of $\sim 15 \mu \mathrm{m}$ due to prior processing. Each coupon was prepared by grinding to 600 grit on $\mathrm{SiC}$ paper and subjected to degreasing in industrial alcohol immediately prior to exposure. A number of coupons of each alloy were initially placed in the relevant furnace for each exposure condition. A coupon was subsequently removed at a predetermined time and subjected to microstructural analysis. The remaining coupons within the furnace were therefore subjected to periodic cooling as each coupon was removed. The samples exposed to steam were cooled to room temperature to allow access to the chamber in order to remove each coupon. The air samples were only subjected to minor cooling $<30^{\circ} \mathrm{C}$ as the furnace door was opened for the removal of each coupon. The sample oxidation conditions and exposure lengths are shown in Table 2.

TABLE 1. Nominal composition of IN617 and IN625 / wt\% [6,7]

\begin{tabular}{ccccccccccccccc}
\hline \hline Alloy & $\mathrm{Ni}$ & $\mathrm{Co}$ & $\mathrm{Mo}$ & $\mathrm{Nb}(+\mathrm{Ta})$ & $\mathrm{Cr}$ & $\mathrm{Al}$ & $\mathrm{C}$ & $\mathrm{Ti}$ & $\mathrm{Mn}$ & $\mathrm{Fe}$ & $\mathrm{Si}$ & $\mathrm{S}$ & $\mathrm{Cu}$ & $\mathrm{B}$ \\
\hline IN6176 & $\mathrm{Bal}$ & 12.5 & 9 & 0 & 22 & 1.15 & 0.1 & 0.6 & 1.0 & 5 & 1 & 0.0015 & 0.5 & 0.006 \\
$\mathrm{IN} 6257$ & $\mathrm{Bal}$ & 1 & 9 & 3.65 & 21.5 & 0.4 & 0.1 & 0.4 & 0.5 & 5 & 0.5 & 0.015 & 0 & 0 \\
\hline \hline
\end{tabular}

TABLE 2. Details of the oxidation conditions studied. All exposures were performed at $750^{\circ} \mathrm{C}$ and atmospheric pressure

\begin{tabular}{ccc}
\hline \hline Environmental Conditions & \multicolumn{2}{c}{ Exposure Times (h) } \\
& IN617 & IN625 \\
\hline 100\% steam & $100,500,1000,2000,3000$ & $100,1000,2000,3000$ \\
$50 \%$ steam + 50\% argon & $100,300,1000,2000,3000$ & $100,300,1000,2000,3000$ \\
Atmospheric air & $100,450,1000,2000,3000,4200$ & $100,500,1000,2000$ \\
\hline \hline
\end{tabular}

In order to produce the appropriate exposure conditions in steam (carried out at the National Physical Laboratory, UK), water was initially purified and de-aerated by first boiling from a de-ionised external reservoir, condensing through a still and was subsequently stored in metallic containers under a positive pressure of nitrogen gas. The purified water was then introduced into the end of a tube furnace, gasifying on contact and flowing over the samples before exiting through a bubbler at the end of the furnace. The level of dissolved oxygen in the steam was of the order of $150 \mathrm{ppb}$. For the $100 \%$ steam exposures, liquid water was introduced to the end of the furnace at a rate of $0.1472 \mathrm{ml} \mathrm{min}^{-1}$. For the $50 / 50 \%$ steam/argon gas mixture, liquid water and gaseous argon were introduced at a rate of $0.0736 \mathrm{ml} \mathrm{min}^{-1}$ and $100 \mathrm{ml} \mathrm{min}^{-1}$ respectively at room temperature and atmospheric pressure to produce the required gas composition by volume. The samples oxidised in air were placed in ceramic crucibles in a standard laboratory furnace.

After exposure the IN617 100\% steam samples were nickel plated in order to protect the oxide layer. Samples were then cross-sectioned using a silicon carbide high speed cutting wheel, mounted in conductive Bakelite, ground and polished to a $1 \mu \mathrm{m}$ finish before undergoing final polishing using alkaline based $0.05 \mu \mathrm{m}$ colloidal silica. The samples were then submerged in methanol and subjected to ultrasonic agitation to remove excess colloidal silica. A range of analytical equipment has been used in this investigation. A Carl Zeiss (LEO) 1530VP Field Emission Gun Scanning Electron Microscope (SEM) with an EDAX Pegasus Energy Dispersive X-ray Spectrometer (EDX) system was used to produce images for the scale measurements and the EDX maps. In-Lens imaging mode was also used to produce high magnification images to investigate the voids and scale microstructure. An FEI Nova Nanolab S600 Dual Beam Focused Ion Beam SEM (FIBSEM) has been used to produce area specific thin foil samples for analysis in a JEOL 2000FX thermionic tungsten filament Transmission Electron Microscope (TEM).

Scale thickness measurements were performed on SEM micrographs by tracing a line along the top and bottom boundary of the scale and taking an average of the distance between the lines using the software package ImagePro Plus 5.0. Where scale thickness measurements were inclusive of alloy protrusions the bottom boundary of the scale was taken to be at the top of the protrusion. The measurement procedure was repeated on nine randomly spaced micrographs and an average of these distances was then determined for each sample. The standard error in the thickness measurements was then calculated based on 95\% confidence intervals. 


\section{RESULTS}

\section{Overview of Oxidation and Substrate Microstructure}

Electron backscatter diffraction image quality maps on cross-sectioned samples both before and after exposure show that the surface preparation procedure, prior to oxidation, introduces matrix damage into the substrate up to a maximum depth of $15 \mu \mathrm{m}$. Upon exposure to the oxidising environment the damaged surface layer undergoes recrystallisation into a fine grained surface layer which exhibited small grains $\sim 10 \mu \mathrm{m}$ in diameter, with grains observed as small as $1 \mu \mathrm{m}$ at the alloy scale boundary where the damage was initially most severe. Examples of the fine surface grain structure feature in earlier work by the authors [8]. The result of the surface preparation was to standardise the surface conditions of each alloy prior to exposure.

Figure 1 is a comparison of each alloy exposed for $2000 \mathrm{~h}$ to high temperature air or steam environments. The micrographs show the formation of similar prominent features in each alloy under each condition. These are a continuous outer scale, an internally evolved phase and the development of voids on or near the alloy/scale boundary. The outer surface of the air oxidised samples feature a high degree of topology through the growth of facetted plate shaped crystals and the development of a generally irregular scale. The plate shaped crystals were a very common feature on IN617, being most prominent in shorter exposures, and grew preferentially perpendicular to the surface. The plate shaped crystals were less common on IN625 and had a wider range of preferred orientations. The scales grown in steam exposures developed a relatively smooth outer surface and were also notably thicker than those formed in air after similar exposure times.
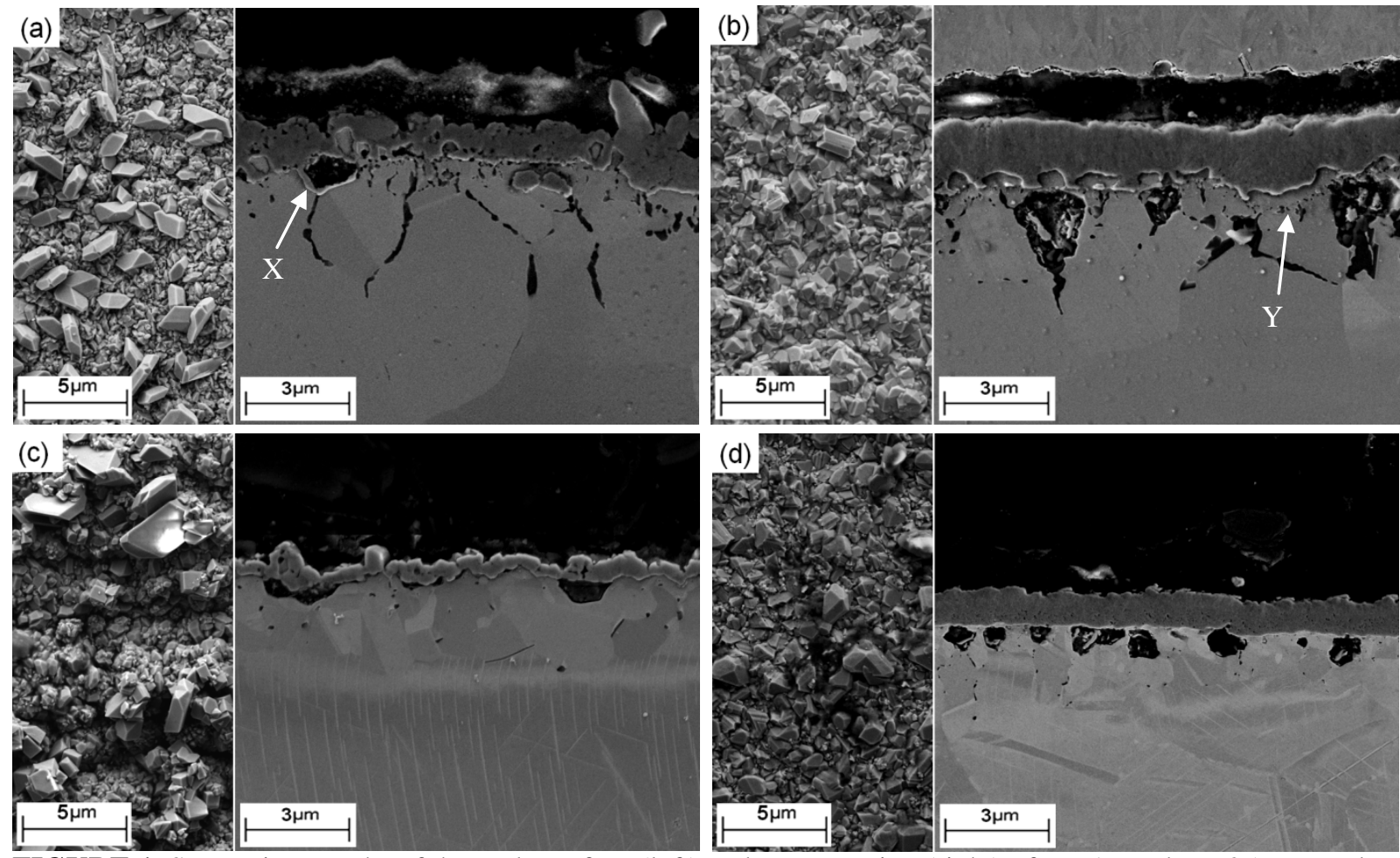

FIGURE 1. SEM micrographs of the scale surface (left) and cross-section (right) of IN617 and IN625 exposed to air or steam for $2000 \mathrm{~h}$ at $750^{\circ} \mathrm{C}$ and atmospheric pressure, a) IN617 - air, b) IN617 - steam, c) IN625 - air, and d) IN625 - steam.

\section{Alloy Scale boundary}

After oxidation the alloy/scale boundary was most irregular in samples of IN617, as shown in Figure 1, exhibiting different features between the air and steam environments. In air numerous alloy protrusions into the scale were observed, which were often elongated perpendicular to the surface and in the earlier stages of oxidation, $\sim 100 \mathrm{~h}$, were observed to protrude to the surface of the scale. Further irregularity of the alloy/scale boundary in conjunction with thick areas of the scale, labelled $X$ in Figure 1(a), was linked to the formation of voids and will be discussed later. The protrusions in all IN617 samples were often conical in shape which can result in apparent metallic inclusions when viewed in cross section, 3D slice and view imaging techniques have show there to be no metallic inclusions in the scales [8]. Alloy protrusions into the scale were also a prominent 
feature in IN617 steam exposed samples but were confined to only protrude into the lower half of the scale and were more rounded in shape. The protrusions grew in every direction with time but favoured lateral growth near the alloy/scale boundary, becoming considerably wider at longer exposure times. The absolute protrusion depth increased with time but decreased relative to the total scale thickness, protruding approximately half way through the scale at $100 \mathrm{~h}$ and only a third at $3000 \mathrm{~h}$. The occurrence of thick areas of scale, which extend into the alloy as shown in the air exposed samples, were not observed in the steam exposed samples within the maximum exposure time of $3000 \mathrm{~h}$.

The alloy/scale boundary of IN625 was more regular than that of IN617. The air exposed samples only very rarely had alloy protrusions in them but did exhibit similar void formation to IN617 at the alloy scale boundary. The appearance of thick regions of scale due to inward scale growth into the alloy did not occur as often as in the air exposed IN617 samples. The IN625 steam exposed samples had the most regular alloy/scale boundary of all exhibiting no protrusions and voids that often had some matrix material separating them from the scale. Occasionally inward scale growth was observed and is discussed, along with void morphology, in a later section.

\section{Scale and Subscale Region Chemistry}

EDX maps of IN617 and IN625 exposed to high temperature steam for $2000 \mathrm{~h}$ are presented in Figure 2 and Figure 3 respectively. The maps show that the scale comprises mainly of chromium and oxygen, consistent with chromia. The scales were also enriched in titanium near the alloy/scale boundary for both alloys. Small regions of high titanium concentration were also observed on the surface of the scales which is consistent with other studies and suggests the formation of $\mathrm{TiO}_{2}[9,10]$. IN625 air exposed samples exhibited similar diffuse titanium enrichment in the scale near the alloy/scale boundary, however, in IN617, titanium in the scale was mostly concentrated in small volumes on the surface.

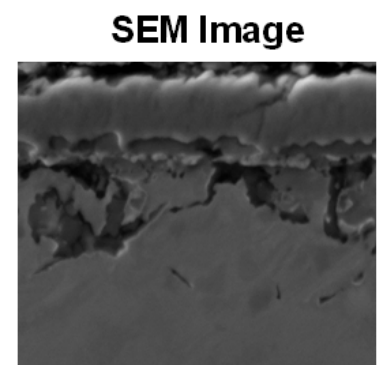

Titanium

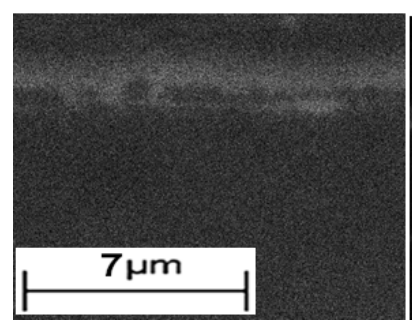

Nickel

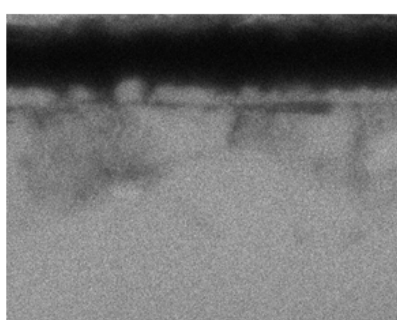

Aluminium

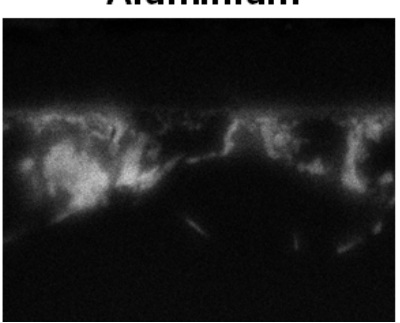

Chromium

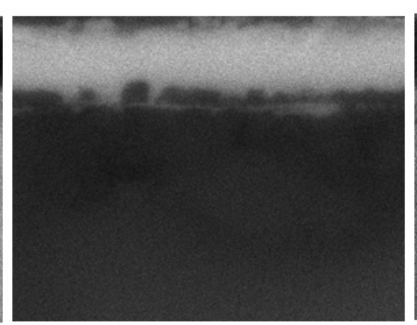

Niobium

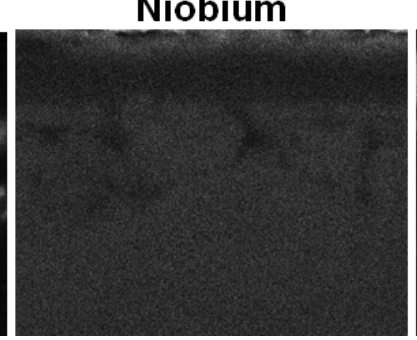

Molybdenum

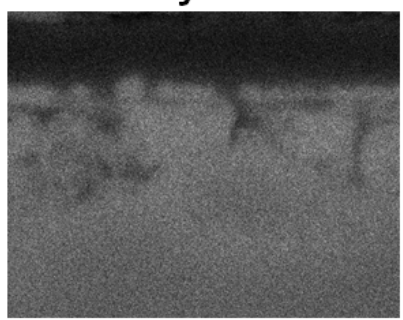

Oxygen

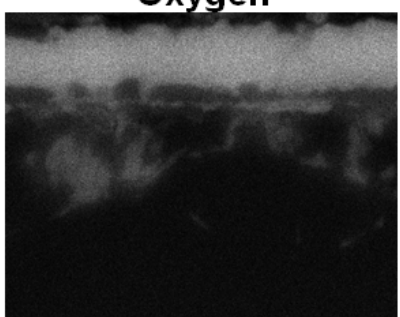

FIGURE 2. EDX maps of a cross-sectioned IN617 sample oxidised in 100\% steam for $2000 \mathrm{~h}$.

The darkly contrasted phase, shown in Figure 1, which grows internally in both alloys within the fine grained region and forms more extensively in IN617 than IN625, comprises of aluminium and oxygen and was confirmed by both EDX and selected area electron diffraction to be alumina, consistent with the observation of other studies [10,11,12]. Figure 2 and Figure 3 show the extent of alumina formation in IN617 and IN625 respectively. Earlier work by the authors involving 3D imaging techniques has shown that alumina forms as an extensively interconnected network firstly near the alloy scale boundary as small particles but then as large plate and rod shaped particles growing preferentially down grain boundaries as oxidation proceeds [8]. IN617 shows a greater extent of alumina formation than IN625 with a large proportion forming in conjunction with the voids. EDX on thin foil IN617 samples prepared using FIB milling showed that alumina particles are not observed to form in the protrusions but are instead confined to a defined plane underneath the protrusions which also coincides with the maximum thickness of the scale, examples of this are highlighted by the points labelled Y in (b). EDX spot analysis of the protrusions showed them to have higher concentrations of chromium, aluminium, cobalt and notably molybdenum when compared to regions deeper within the alloy still within the chromium depletion zone.

Figure 3 shows that niobium was enriched in IN625 samples directly beneath the scale, this was in conjunction with the absence of the preferentially orientated niobium rich $\gamma^{\prime \prime}$ phase which forms throughout the bulk alloy and can be seen as straight particles in the lower portion of the niobium EDX map and as the straight, lightly 
contrasted, particles in Figure 1(c) [13]. Molybdenum was also enriched in discreet areas underneath the scale in IN625 labelled $\mathrm{X}$ in Figure 3. Caution must be exercised whilst analysing the niobium and molybdenum distributions via EDX mapping as peak resolution was sacrificed to attain a strong signal, however, owing to the proximity of the $\operatorname{Mo}(\operatorname{L} \alpha)$ and $\mathrm{Nb}(\mathrm{L} \beta)$ peaks it is likely that some peak overlap occurred, as highlighted by Figure 2, as there is no niobium present in IN617.

SEM Image

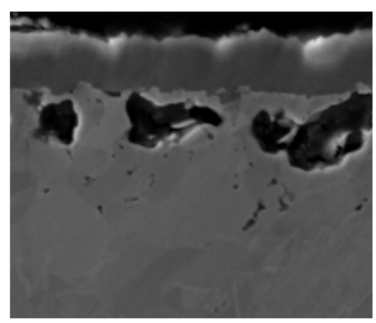

Titanium

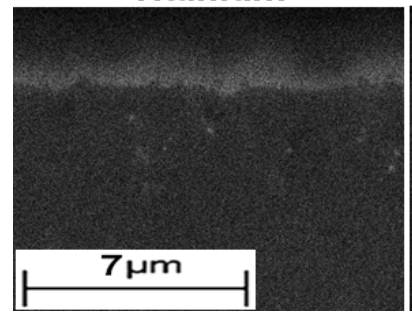

Nickel

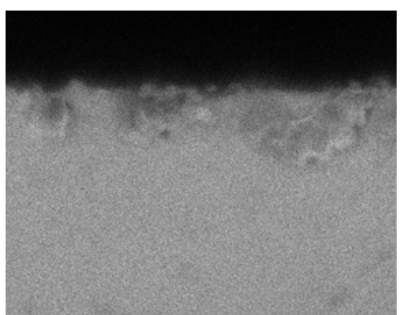

Aluminium

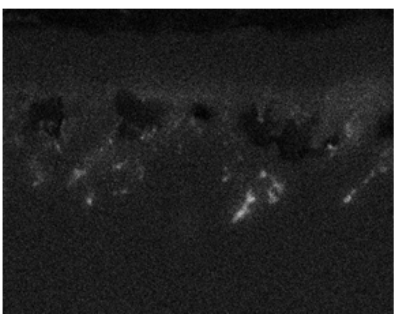

Chromium

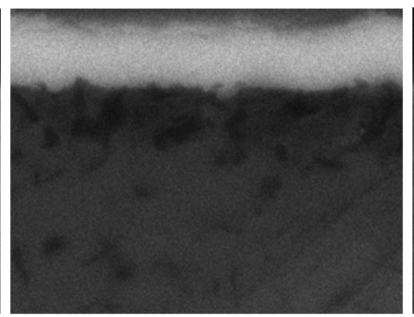

Niobium

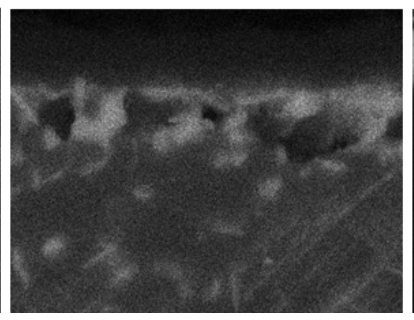

Molybdenum

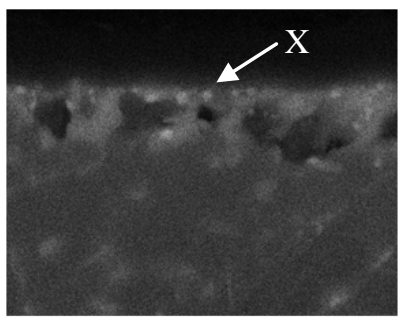

Oxygen

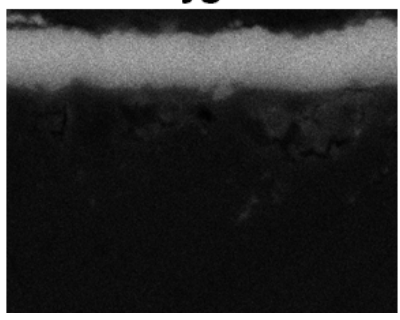

FIGURE 3. EDX maps of a cross-sectioned IN625 sample oxidised in $100 \%$ steam for $2000 \mathrm{~h}$.

Both alloys exhibited a region below the scale that was depleted in chromium in both air and steam exposure samples, reaching in IN617 approximately half the initial chromium concentration at the alloy scale boundary for $3000 \mathrm{~h}$ exposures in steam. The fine grained region near the surface of each alloy was preferentially depleted in chromium over the larger substrate grains resulting in a well defined transition from the depletion zone composition to the relatively unaffected large substrate grains with composition representative of the bulk alloy. Preferential chromium depletion within the fine grained surface region was less pronounced in IN625 steam exposed samples as the substrate also had a small grain size resulting in a more gradual, idealised, return to the unaffected alloy composition.

\section{Scale and Void Microstructure}

The scales which formed on both IN617 and IN625 during exposure to steam exhibited two distinct microstructures in their inner and outer regions. Figure 4 (a) and (b) show fine oxide grains on the inner side and large, often columnar shaped oxide grains on the outer side of the scale; growth of this type has been seen in other investigations for other oxide systems [3,14,15]. The large oxide grains of IN617 showed a columnar morphology which became distinguishable from the fine grained region in exposures longer than $1000 \mathrm{~h}$. The interface at which the scale microstructure changes from fine grained to large grained was reasonably flat for IN625 but irregular for IN617. Scales which were formed in air, on both IN617 and IN625, had equiaxed grains, slightly larger than the fine grains formed in steam, with the occasional large faceted plate shaped crystal on the surface, as shown in Figure 1. There did not appear to be any subscale microstructural feature which related to the formation of the observed plate shaped crystals consistent with the work of other authors [14].

Figure 4 (c) and (d) show the presence of micro-pores, $<10 \mathrm{~nm}$ in diameter, in the lower, fine grained region of the steam exposure scales for both IN625 and IN617. The pores are larger and more common near the alloy/scale boundary then get increasingly smaller and less common towards the columnar grain interface. The columnar grained region showed no porosity on either IN625 or IN617. IN617 scales exhibited a high degree of porosity in the inner part of the scale in the shorter exposure samples but had significantly reduced porosity in the longer exposed samples when compared to IN625. Air exposed sample scales did not exhibit porosity.

Voids formed in both alloys under all exposure conditions and are present in samples oxidised for the minimum 100h, for a comparison between void features developed under the different conditions refer to Figure 1. IN625 and IN617 air exposed samples developed voids on the alloy/scale boundary with the occasional void forming on the large substrate grain boundary below the fine grained surface region. The voids usually had an aspect ratio favouring the widest point being at the alloy scale boundary. For IN617 it was common for chromia to form on the inner surface of the voids, labelled X in Figure 1, in samples for all exposure times which eventually lead to the void becoming included in the scale whilst retaining its original shape. 

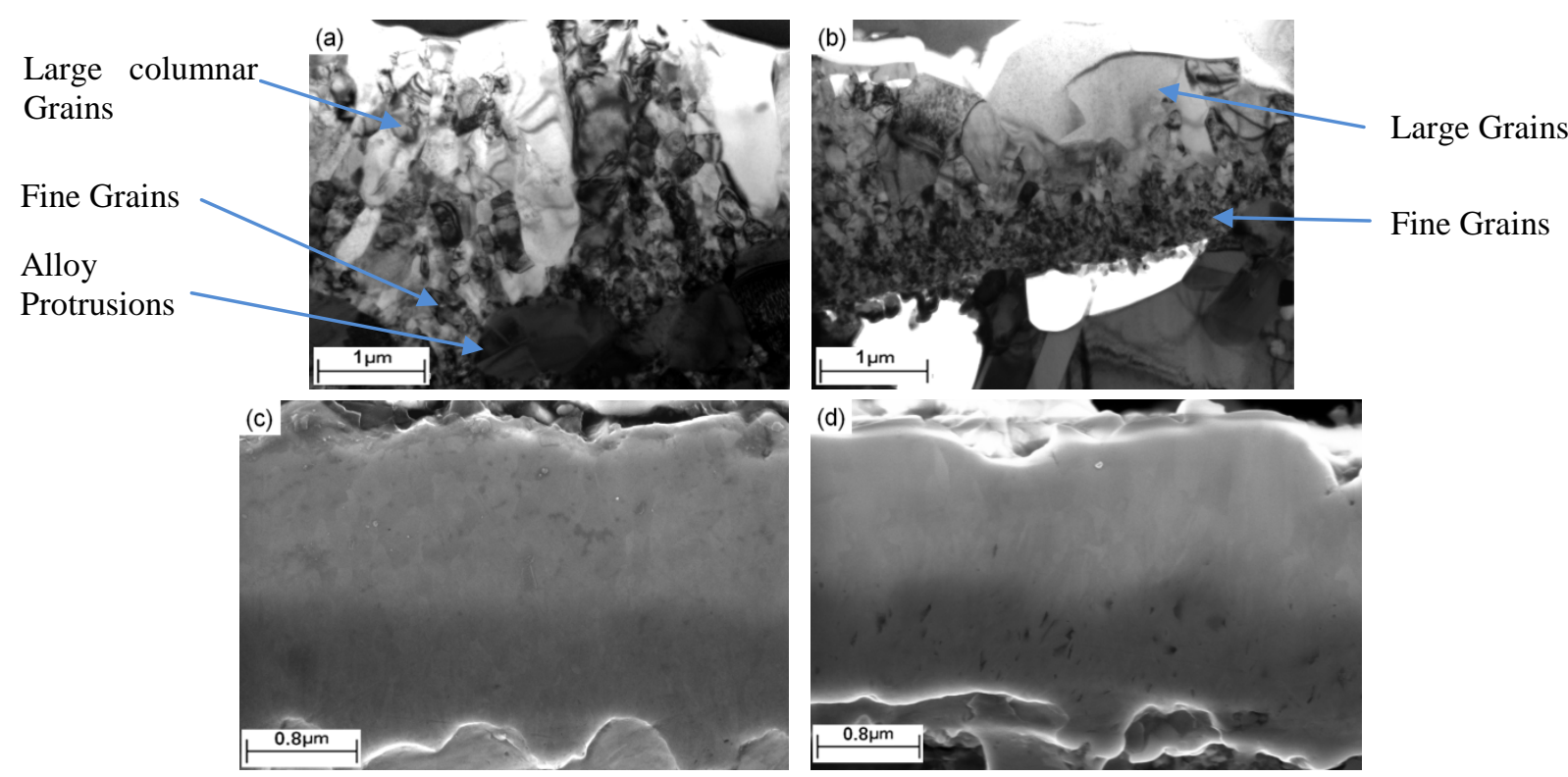

FIGURE 4. Micrographs of the scale microstructure after exposure to $50 \%$ steam/argon at $750^{\circ} \mathrm{C}$ for $3000 \mathrm{~h}$, including a) TEM micrograph of the scale formed on IN617, b) TEM micrograph of the scale formed on IN625, c)

SEM micrograph of the scale formed on IN617, and d) SEM micrograph of the scale formed on IN625,

The voids in samples exposed to steam were far more common and had notably different morphologies. IN625 steam exposed samples developed voids on the alloy/scale boundary that were more spherical in shape than under air exposures, with their widest point being lower than the alloy/scale boundary. The voids were relatively evenly distributed and regular in shape when compared to IN617 that had larger, but less numerous, voids that generally penetrated deeper into the alloy. The voids in IN617 steam exposed samples initially formed on the alloy scale boundary, as shown in Figure 5 (a), but as oxidation proceeds alloy protrusions in-between the voids and the alloy/scale boundary continue to grow and coalesce resulting in the voids appearing set into the alloy, as shown in Figure 5 (b). The shape of voids in IN617 steam exposed samples was heavily dependent on the surrounding alumina, often forming with straight edges that followed the contours of the near surface fine grain structure, the voids formed in IN617 were generally larger.

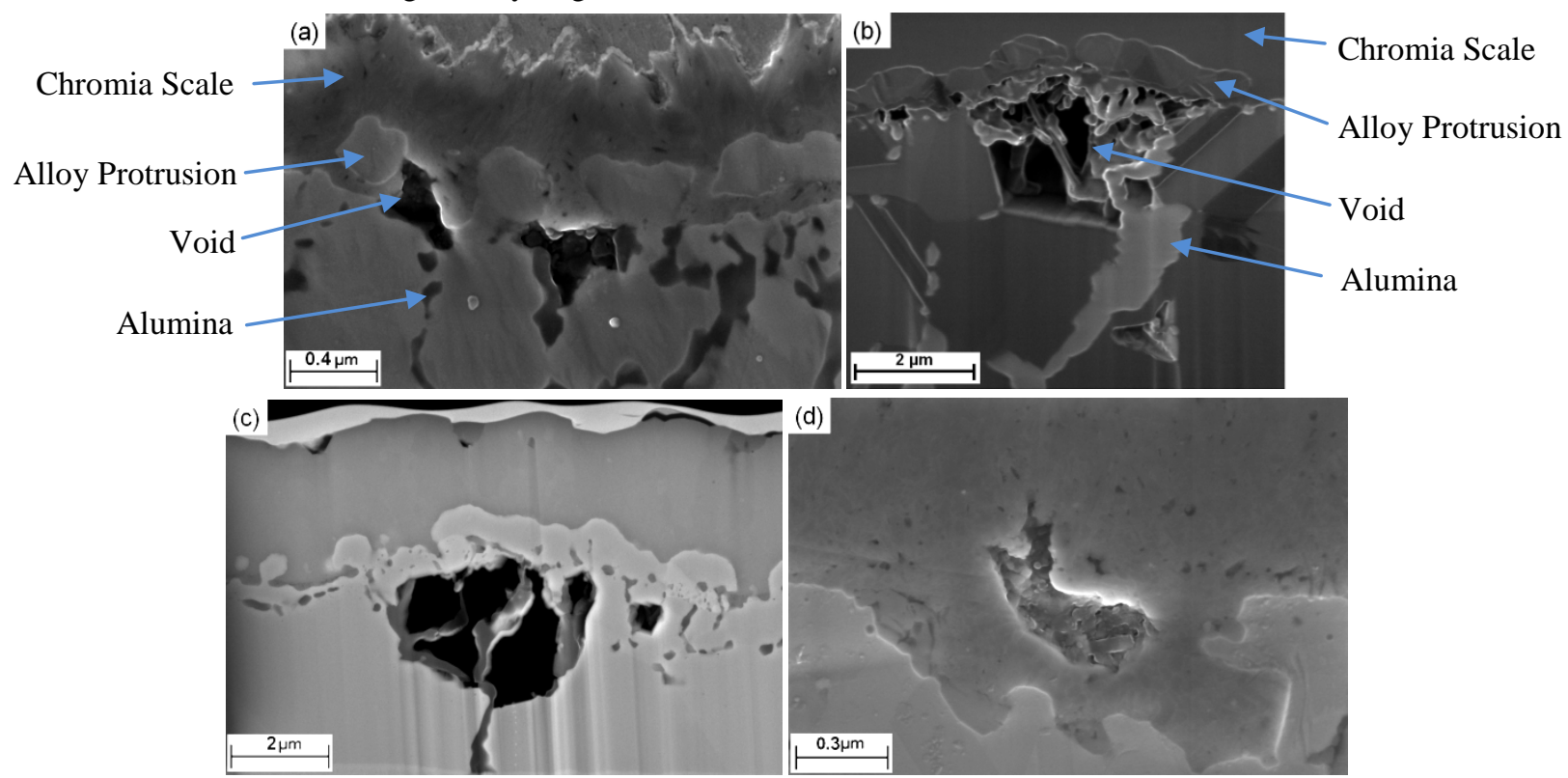

FIGURE 5. SEM micrographs of various void structures. a) IN617 sample exposed to $100 \%$ steam at $750^{\circ} \mathrm{C}$ for $100 \mathrm{~h}$ showing void development on the alloy/scale boundary, b) IN617 sample exposed to $100 \%$ steam at $750^{\circ} \mathrm{C}$ for $3000 \mathrm{~h}$ and prepared using FIB milling showing alumina formation on the inner surface of the voids, c) Thin

foil IN617 sample prepared using FIB milling exposed to $100 \%$ steam at $750^{\circ} \mathrm{C}$ for 3000 h showing internal alumina filaments within the voids, and d) IN625 samples exposed to $100 \%$ steam at $750^{\circ} \mathrm{C}$ for $2000 \mathrm{~h}$ showing void formation in the scale as the inner surface of the void is oxidised. 
In all cases of void formation under the scales of both IN617 and IN625 it was common to see alumina filaments crisscrossing their interior as shown in Figure 5(b) and (c), which were prepared using ion beam milling. The figures also show that alumina lined the majority of the inner surface of the voids for IN617.

After extended periods of exposure to steam environments, IN625 occasionally exhibited inward scale growth in to the void regions, as shown in Figure 5(d). Chromia was observed to form on the inner boundaries of the void whilst at the same time the outer scale boundary of the void appeared to dissociate, causing void to form in the lower region of the scale. Void space which had been taken up into the scale in this manner was confined to the lower region of the scale and was significantly smaller than the original void. The occurrence of inward scale growth became increasingly more common at longer exposure times.

\section{Oxidation Kinetics}

Scale thickness measurements are given in Figure 6. Both alloys developed a thin oxide and exhibited the same overall trend in that the rate of scale thickening in each environment occurs in the following order air $<50 \%$ steam/argon < 100 steam. Measurements made on IN617 samples are more prone to scatter due to the irregular alloy/scale boundary. The rate of oxide thickening was slightly higher in IN617 than IN625 in air, however, in environments inclusive of steam the difference was less pronounced.
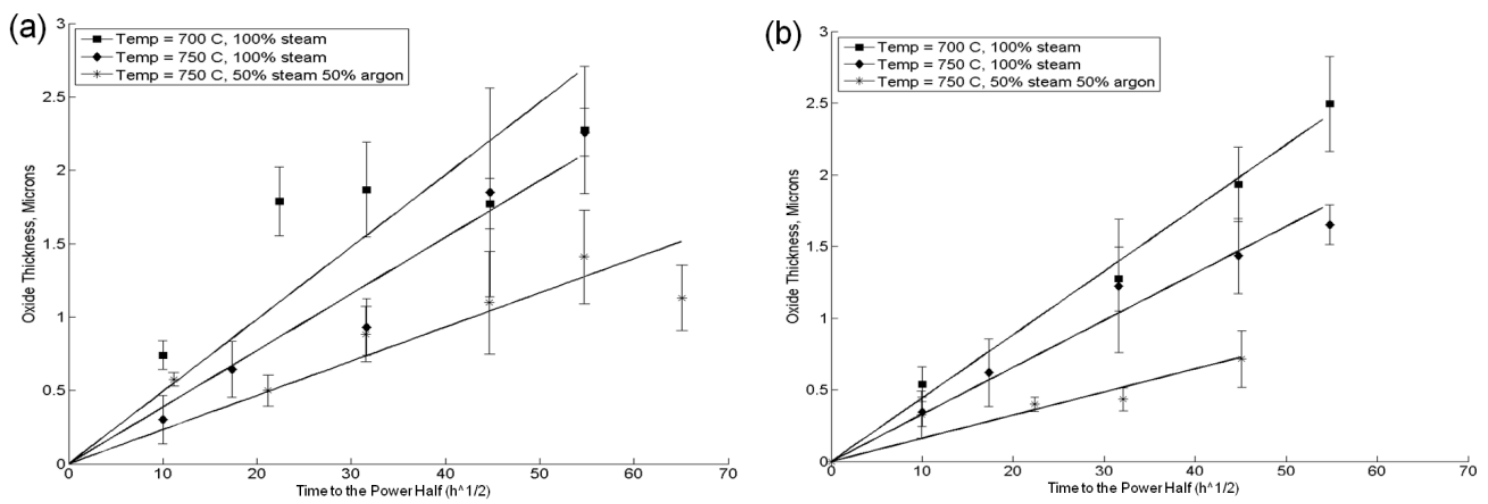

FIGURE 6. Graphs of scale thickness measurements against time to the power half for exposures to air, $100 \%$ steam and $50 \%$ steam/argon mixtures at $750^{\circ} \mathrm{C}$ and atmospheric pressure for a) IN617 and b) IN625

\section{DISCUSSION}

The formation of a duplex scale microstructure of outer large, and in the case of IN617 columnar, grains and inner fine grains has been seen in a number of other investigations involving oxidation in steam and has been attributed to the existence of concurrent growth mechanisms occurring both at the scale surface, via cationic diffusion, and at the alloy/scale boundary, via the inward diffusion of oxygen or hydroxyl ions down grain boundaries or other short circuit diffusion paths [3]. Alternatively, though not mutually exclusive, scale growth at the alloy scale boundary could occur through gas transport of $\mathrm{H}_{2} \mathrm{O}$ via the motion of pore interfaces within the scale as first proposed by Rahmel and Tobolski [5]. The porosity in the lower part of the scale, seen in both alloys, could be a remnant of the original growth of the scale, however, evidence of void uptake into the scale as IN625 undergoes inward scale growth into the void regions, shown in Figure 5(d), suggests a mechanism by which the scale can dissociate on the side furthest from the metal as suggested by the Rahmel-Tobolski mechanism. This would also suggest that pores within the scale would undergo a similar process and therefore must be continuously generated within the scale. The main mechanism that could generate pores at or near the alloy/scale boundary would be the condensation of vacancies produced at the columnar grain interface as chromium diffuses towards the surface. This mechanism would also explain the small $(<10 \mathrm{~nm})$ size of the pores. The pores, and voids taken up into the scale in IN625, are observed to be smaller the further from the alloy/scale boundary they are, suggesting that extra chromium and oxidant was supplied to the pore resulting in a greater rate of oxide growth on the pore's alloy side interface than there was oxide dissociation on the outer side. There would therefore have to be a mechanism on top of cationic diffusion of chromium that supplies extra oxidant i.e. via the diffusion of oxygen or hydroxyl ions via short circuit paths, again supporting the development of the duplex scale microstructure. Alternatively the gradient in pore size could be due to the a higher number of cation vacancies near the alloy/scale boundary where the $\mathrm{p}\left(\mathrm{O}_{2}\right)$ is lowest, resulting in greater vacancy condensation and therefore a greater volume of pores. The absence of inward scale growth into the voids in IN617 could be as a result of the formation of a protective layer of alumina on the inner surface of the void or the development of alloy protrusions 
inbetween the void and the scale but also the increased availability of aluminum in the alloy, which reacts with oxygen that diffuses into the alloy, reduces the $\mathrm{pO}_{2}$ under the scale and prevents gas transport across the void.

IN617 has a higher aluminum content resulting in more extensive internal alumina formation. This could be linked with the existence of alloy protrusions observed in IN617 but not in IN625. The protrusions observed in IN617 are similar to metallic nodules observed on the surface of oxidised silver-indium alloys by Guruswamy et al. (1986) [16,17]. The alumina occupies a greater volume than the original aluminium rich alloy matrix resulting in compressive stresses within the alloy substrate in the internal oxidation region. To relive the build up of stress material is extruded into the surface oxide to form metallic protrusions. An alternative explanation for the formation of the protrusions would be inward growth of the scale, this would lead to alumina particles being incorporated into the lower part of the scale as the alloy regresses, however, no alumina particles are seen in the scale [18]. Instead the protrusions are absent of any alumina particles that should have formed early on, near the original alloy surface. The fine alumina particles near the surface form in a defined plane underneath the protrusions demarcating the original alloy/scale boundary in an earlier stage of oxidation. The alumina particles remain immobile as they are anchored in place due to their high degree of interconnectivity, shown in earlier work [8].

Differing plasticity within the scale could be the cause of the protrusions development which remain confined to the inner portion of the scale and prefer lateral growth opposed to extending deeper into the scale. IN625 exhibits a greater porosity near the alloy/scale boundary which then reduces towards the centre of the scale suggesting that vacancies within the scale favoured coalescence near the alloy boundary. Protrusions in IN617 could favour lateral growth near the alloy/scale boundary due to the increased plasticity of the scale in this region as a result of chromium vacancy condensation. The suppression of pore formation would then be expected in IN617 scales, hence the greater porosity observed in IN625 scale.

The voids form in both alloys in both air and steam environments within the chromium depletion zone and down grain boundaries. Oxidation of pure metals is accompanied by the regression of the metal surface, however, in alloy systems the diffusivities of the various elements are not equal, the diffusion kinetics can result in a divergence form equilibrium conditions, i.e. the chromium depletion zone. Enhanced chromium diffusion down grain and matrix/alumina interphase boundaries facilitates the formation of voids opposed to metal regression by providing short circuit diffusion paths that inject vacancies, generated at the alloy/scale boundary, into the alloy. Coalescence of these vacancies, assuming they are not able to annihilate at points within the alloy, result in the formation of voids similarly to the Kirkendall effect [4]. Furthermore, the formation of the alumina, shown in previous work to form into a plate and rod shaped network, could enhance chromium diffusion by providing a greater density of short circuit diffusion paths than would ordinarily exist from grain boundaries alone [8]. Enhanced diffusion of chromium along grain boundaries explains, at least in part, why the fine grained surface region was preferentially depleted of chromium over the larger grains of the substrate in the exposures excluding IN625 in steam.

The kinetics of diffusion within the chromium depletion zone dictates the form of the voids. The observed difference in void shapes between air and steam exposed IN625 samples could be as a result of the increased chromium diffusion rate necessary to form the thicker scale in the steam exposures. The voids which develop in air exposures are closer in form to alloy regression as the uptake of chromium into the scales was lower allowing more time for the alloy to equilibrate and undergo homogenous alloy regression.

The proposed mechanism of compressive stresses, generated by the internal oxidation of alumina, inducing protrusions would be expected to inhibit the formation of voids, as vacancies would be annihilated on the expanding alumina crystals, however, voids are a prominent feature in both alloys. Voids in IN617 are, without exception, associated with areas of extensive alumina formation. High magnification images of voids in IN617 show the void surfaces to be coved by a thin layer of alumina which gives the voids structural integrity. The existence of alumina filaments across the voids suggests that the formation of alumina precedes that of the voids. Alumina forms on the boundaries in the fine grained surface region and acts to enhance the short circuit diffusion in that region, resulting in the condensation of vacancies around the alumina. Concurrently oxidant continues to diffuse into the alloy forming alumina deeper into the alloy and on the inner surface of the newly formed voids.

Both alloys exhibit the same relationship between growth rates in the three atmospheres. The higher rate of oxidation in the IN617 air exposed samples over IN625 could be linked with the formation of protrusions which increase the effective surface area of the alloy/scale boundary, reduce the effective thickness of the scale and disrupt the scale potentially inducing fissures micro-cracks allowing oxidant access to the underlying voids as marked by the point X in Figure 1(a) [19]. Similarly the initial faster rate of oxidation in IN617 steam samples over IN625 could be as a result of the protrusions; this becomes less pronounced as the scale thickens as the protrusions in steam exposed samples are confined to the region near the alloy/scale boundary. IN625 grows a slightly thicker scale on average at longer exposures due to inward scale growth into the regions of the voids which does not occur in IN617 due to the void being shielded by alumina and the formation of alloy protrusions. 


\section{CONCLUSIONS}

Alloys IN617 and IN625 have been oxidised in both air and steam environments. Both alloys developed a thin protective scale and showed similar overall scale growth kinetics but exhibited notable differences in their microstructure. All steam exposed samples showed a greater rate of oxidation than those exposed to air. The presence of steam alters the scale microstructure for both alloys into an outer large grained region with a fine grain inner region. The fine grained inner region of the scale on both alloys showed evidence of porosity with greater porosity near the alloy/scale boundary. The evolution of alloy protrusions into the scale of IN617 reduced porosity within it. Voids form in each alloy under both air and steam environments and have been attributed to differing diffusion rates of elements within the alloy. In steam environments voids are eventually taken up into the scale in IN625 but in IN617 the voids remain in the alloy shielded from oxidation by a thin layer of internal alumina and the development of alloy protrusions. The higher content of aluminum within IN617 results in a more extensive alumina network, which reduces the $\mathrm{pO}_{2}$ in the underlying alloy and could potentially inhibit gas transport across the voids thus preventing chromia formation within the voids.

Both alloys exhibited good oxidation resistance with parabolic scale growth kinetics. Neither alloy distinguished itself as being more suitable for application in an ultra-supercritical steam systems from microstructural analysis over the investigated exposure times, however, key differences in the development of internal alumina, voids and alloy protrusions could affect scale adherence at longer exposures. Further testing is required to replicate more closely the steam conditions encountered in ultra-supercritical systems, namely high pressure, steam flow rate, surface geometry and steam composition, in order to assess the long term viability of these alloys for continued oxidation resistance.

\section{ACKNOWLEDGEMENTS}

We would like to acknowledge financial support from both EPSRC (Grant No. EP/G037345/1) through the Doctoral Training Centre in Efficient Fossil Energy Technologies and Alstom Power Ltd. We would also like to express our gratitude to the National Physical Laboratory for supplying the steam exposed materials with the support of the UK Department for Business, Innovation and Skills.

\section{REFERENCES}

1. N. Birks, G. H. Meier, and F. S. Pettit, Introduction to the High-Temperature Oxidation of Metals. 2nd edition, New York: Cambridge University Press, 2006, pp. 76-82.

2. D. Young, High Temperature Oxidation and Corrosion of Metals, London: Elsevier, 2008, pp. 455-492.

3. I. Wright, and R. Dooley, "A review of the oxidation behaviour of structural alloys in steam", International Materials Reviews, 55, pp. 129-167 (2010).

4. W. Quadakkers, and J. Zurek, “Oxidation in Steam and Steam/Hydrogen Environment”, in Shrier's Corrosion, 4th Ed, London: Elsevier, 2010, pp. 407-456.

5. $\quad$ S. Saunders, M. Monteiro, and F. Rizzo, Progress in Materials Science, 53, pp. 775-837 (2008).

6. INCONEL alloy 617, Technical Bulletin, Special Metals Corporation, SMC-029 (2005, Mar 05).

7. INCONEL alloy 625, Technical Bulletin, Special Metals Corporation, SMC-063 (2006, Jan 06).

8. D. Gorman, R. L. Higginson, H. Du, G. McColvin, A. T. Fry, and R.C. Thomson, "Microstructural analysis of steam oxidation of IN617 for use in ultra-supercritical steam plants", Materials at High Temperatures, In Press, (2012).

9. A. Duval, F. Miserque, M. Tabarant, J.-P. Nogier, A. Gédéon, Oxidation of Metals, 74, 5-6, pp. 215-238 (2010).

10. E. Essuman, L. R. Walker, P. J. Maziasz and B. A. Pint, "Oxidation behavior of cast Ni-Cr alloys in steam at $800^{\circ} \mathrm{C}$ ", 8th International Charles Parsons Turbine Conference, (2011) .

11. D. Kim, C. Jang, and W. S. Ryu, Oxidation of Metals, 71, pp. 271-293 (2009). 
12. C. Jang, D. Lee, and D. Kim, International Journal of Pressure Vessels and Piping, 85, pp. 368-377 (2008).

13. V. Shankar, K. B. S. Rao, S. L. Mannan, Journal of Nuclear Materials, 288, pp. 222-232 (2001).

14. R. Peraldi, D. Monceau, and B. Pieraggi, Oxidation of Metals, 58, pp. 249-273 (2001).

15. A. Paul, M.J.H. van Dal, A.A. Kodentsov, and F.J.J. van Loo, Acta Materialia, 52, pp. 623-630 (2004).

16. S. Guruswamy, S. M. Park, J. P. Hirth, and R. A. Rapp, Oxidation of Metals, 26, 1/2 , pp. 77-100 (1986).

17. S. W. Guan, H. C. Yi, and W. W. Smeltzer, Oxidation of Metals, 41, 5/6, pp. 377-387 (1994) .

18. F. H. Stott, and G. C. Wood, Material Science and Technology, 4, pp. 1072-1078 (1988).

19. P. Huczkowski, N. Christiansen, V. Shemet, J. Piron-Abellan, L. Singheiser, and W. J. Quadakkers, Fuel Cell Science and Technology, 1, pp. 31 (2004). 